А. А. Емцев, А. В. Поргунёв

ДОПОЛНИТЕЛЬНЫЕ СВЕДЕНИЯ О МИГРАЦИОННЫХ ОСТАНОВКАХ ПИСКУЛЬКИ

В СУРГУТСКОМ РАЙОНЕ ХАНТЫ-МАНСИЙСКОГО

АВТОНОМНОГО ОКРУГА - ЮГРЫ

И ПРОБЛЕМА ОХРАНЫ ВИДА

A. A. Emtsev, A. V. Porgunyov

\title{
ADDITIONAL INFORMATION ABOUT THE LESSER WHITE-FRONTED GOOSE MIGRATION STOPS IN THE SURGUT DISTRICT OF THE KHANTY-MANSIYSK AUTONOMOUS OKRUG - UGRA AND THE PROBLEM OF SPECIES CONSERVATION
}

\begin{abstract}
Аннотация. В результате анализа фотоматериалов охотников с. Сытомино Ханты-Мансийского автономного округа - Югры и их последующего опроса, выявлено место миграционных остановок пискулек в долине Средней Оби. Птицы останавливались у небольшого озера в 3,5 км к востоку от села. Одна раненая особь была найдена 12 сентября 2011 г. у озера на комплексном верховом болоте в 9,5 км к юго-западу от г. Лянтор. С целью сохранения пролетных пискулек и других видов уязвимых животных на территории округа предлагается ввести обязательный экзамен для охотников по определению отдельных представителей региональной фауны, ужесточить штрафные санкции за незаконную добычу, усилить пропаганду бережного отношения к природе и воспитательную работу, в том числе по привитию охотничьей культуры. Обозначены проблемы экономического и организационного характера.
\end{abstract}

Ключевые слова: пискулька; миграционные остановки; охота; охрана; центральная часть Западной Сибири.

Сведения об авторах: Емцев Александр Александрович, ORCID: 0000-0002-1496-0171, SPIN-код: 7450-1370, канд. биол. наук, Сургутский государственный университет; г. Сургут, Россия, alemts@mail.ru; Александр Владиславович Поргунёв, Сургутский лесхоз, г. Сургут, Россия, alprg@inbox.ru.

About the authors: Emtsev Alexander Alexandrovich, ORCID: 0000-0002-1496-0171, SPIN-код: 7450-1370, PhD, Leading Research Officer of Scientific and educational center of the Institute of Natural and Technical Sciences of Surgut State University; Alexander Vladislavovich Porgunyov, Chief Specialist of Surgut Forestry.

Работа выполнена в ходе реализации проекта «Управление ресурсами хозяйственно-ценных видов биоты основных типов экосистем Ханты-Мансийского автономного округа - Югры в условиях их техногенной трансформации» Сургутского государственного университета.

\section{Введение}

Пискулька Anser erythropus (Linnaeus, 1758) - редкий, сокращающийся в численности вид гусей, охраняемый на большей части своего ареала. Согласно оценке, проведенной 6 августа 2018 г., в Красном списке МСОП она внесена в блок Threatened (ТН) - таксоны, находящиеся под угрозой исчезновения, имеет категорию Vulnerable (VU) - уязвимый и критерии A2bcd+3bcd+4bcd [16]. Возможно, внутри обозначенного блока в скором времени произойдет изменение статуса редкости на Endangered (EN) - вымирающий. В Красную книгу Российской Федерации [6] пискулька включена с категорией редкости 2 - сокращающийся в численности вид и, очевидно, сохранит свой статус в следующем издании [5]. Численность взрослых птиц мировой популяции оценивается в 16 000-27 000 особей [16]. 
Согласно современным представлениям, гнездовой ареал пискульки сильно фрагментирован и состоит из отдельных очагов гнездования в узкой полосе лесотундры и южной тундры Евразии [10; 15]. В центральной части Западной Сибири, в пределах Ханты-Мансийского автономного округа Югры (ХМАО - Югры), по данным спутниковой телеметрии, встречаются пролетные птицы, гнездящиеся в Большеземельской тундре [18], на Полярном Урале [9; 19; 20], на юге Ямала [10], в южной части Таймыра $[10 ; 25 ; 26]$, плато Путорана [8; 14] и Фенноскандии [17; 27 и др.].

Для обеспечения эффективной охраны пролетных особей очень важно знать места и продолжительность их остановок, особенности распределения и численность пискулек на таких участках на всем протяжении миграционного маршрута. В XМАО - Югре к настоящему времени они в общих чертах определены [12; 13; 24 и др.]. Однако основная часть работ выполнялась в местах концентрации пискулек на осеннем пролете - Нижнем и Верхнем Двуобье, являющихся водно-болотными угодьями международного значения [1], Двуобье, относящемся к Ключевой орнитологической территории международного значения [3], и некоторых других. Следует указать на недостаточность исследований пространственно-биотопического распределения птиц в весеннее время - как при целенаправленных авиаучетах, так и по данным спутникового мечения [8]. Кроме того, в течение последних нескольких десятилетий остаются слабоизученными или вовсе не обследованными отдельные участки в долине Средней Оби и огромные площади заболоченных междуречий.

В этой связи весьма любопытные сведения дали результаты спутникового слежения за парой мигрирующих пискулек, помеченных в южной части полуострова Таймыр (зона лесотундры) в 1998 г. В начале 2-й декады сентября птицы сделали остановку в долине Средней Оби в окрестностях д. Лямина (рис. 1), где провели около недели [26; T. Aarvak - личное сообщение; К. Е. Литвин - личное сообщение]. С тех пор никакие данные о связях гусей с обозначенным районом не поступали. Тем интересней информация, полученная нами при опросе охотников с. Сытомино, а также предоставленная заведующим зоологическим отделом Эколого-биологического центра г. Сургута А. М. Прокофьевым.

\section{Результаты и их обсуждение}

Сделанные жителями с. Сытомино фотографии свидетельствовали о регулярной их охоте на пролетных гусей. На некоторых снимках были запечатлены добытые пискульки. Выяснение обстоятельств добычи позволило установить, что эти пискульки останавливались у озера в 3,5 км к востоку от села (рис. 1). Охота осуществлялась из замаскированной засидки (скрадка) с подсадными чучелами и профилями водоплавающих птиц, в том числе гусей. Одна особь была добыта 14 мая 2011 г., вторая 17 мая 2011 г. Видовую принадлежность других гусей по имеющимся изображениям достоверно определить не удалось. Возможно, они являлись белолобыми Anser albifrons (Scopoli, 1769). Также не удалось определить птицу, убитую 8 мая 2013 г.

В сентябре 2011 г. в минизоопарк Эколого-биологического центра г. Сургута поступила взрослая пискулька с огнестрельной раной на крыле. По сообщению Александра Михайловича Прокофьева, 12 сентября около оз. Паутльлор примерно в 9,5 км к юго-западу от г. Лянтор (рис. 1) ее подобрал местный житель. Вероятно, гусь был подстрелен во время остановки или выбора места для отдыха. Ему сразу пришлось ампутировать половину крыла. Эта птица прожила в минизоопарке 7 лет (рис. 2).

Таким образом, рассмотренные участки могут использоваться гусями как при осенней, так и при весенней миграции. На основании проведенных в 1977 г. исследований [2] высказано предположение, что болотно-озерные комплексы Сургутского района имеют важное значение для мигрирующих пискулек, особенно весной [21]. Есть этому и более поздние подтверждения [7]. Стоит отметить, что проведенные в центральной части Средней Оби осенние авиаучеты положительных результатов не дали [7; 22; 23]. Очевидно, существует необходимость организации специальных исследований, которые помогут оценить число пролетающих и останавливающихся здесь птиц и в определенных случаях поспособствуют созданию особых зон с ограниченным режимом охоты [11; 24 и др]. 


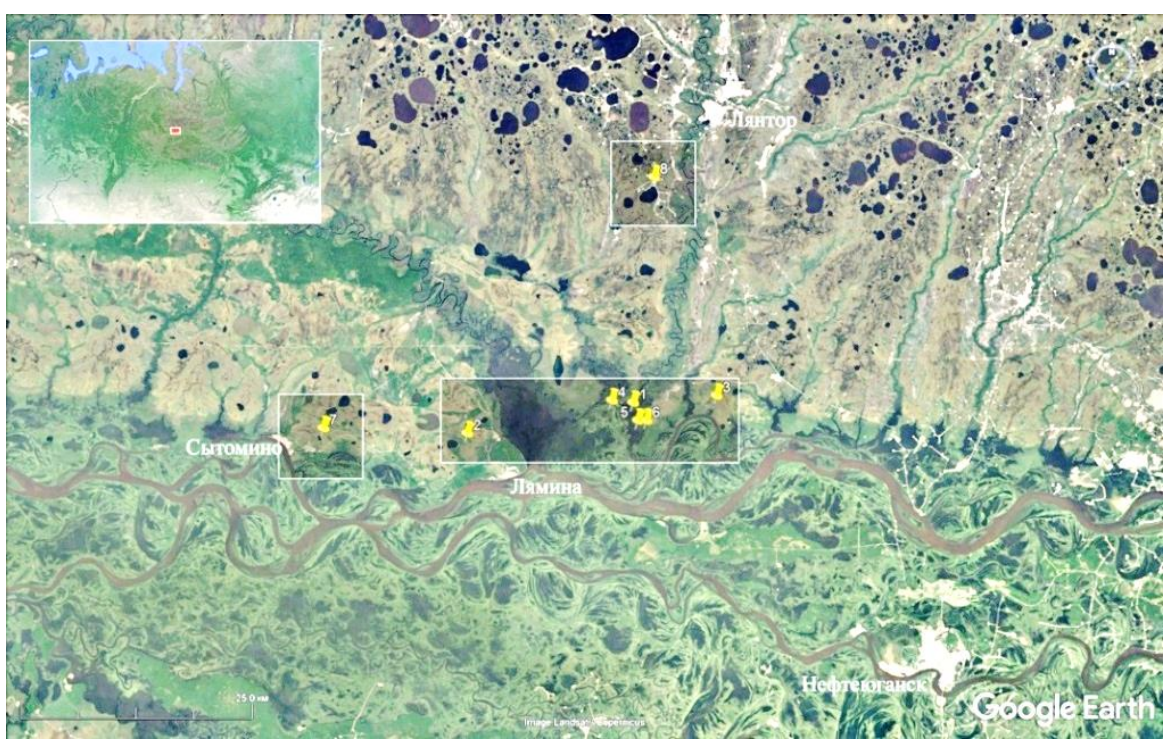

Рис. 1. Места регистраций пискулек в центральной части Ханты-Мансийского автономного округа - Югры, произведенных за два десятилетия.

1-6 - по данным спутникового мечения в сентябре 1998 г., 7 - добыча охотниками в мае 2011 г., 8 - находка раненой особи в сентябре 2011 г.

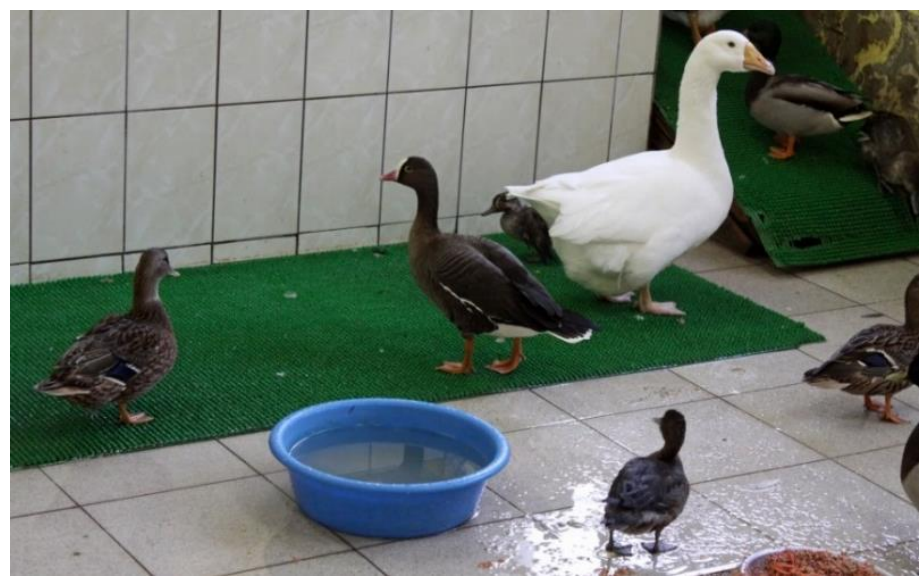

Рис. 2. Пискулька в минизоопарке Эколого-биологического центра г. Сургута, 22 октября 2011 г. (фото А.А. Емцева)

Следующий значимый вопрос, вытекающий из вышеизложенного, касается проблемы охраны вида в охотничьих угодьях и на особо охраняемых природных территориях. Тема незаконной охоты на пискульку и ее масштаба уже поднималась коллегами неоднократно [22; 23 и др.]. Нам бы хотелось акцентировать внимание на нескольких моментах.

1. Незнание частью граждан видовой принадлежности добываемых птиц и правил охоты. В частности, охотники не отличают пискульку от белолобого гуся, на которого разрешена охота, а добычу часто совершают в сумерках, когда диагностические признаки видов не видны или малозаметны. Главными причинами такого явления оказывается слабая мотивация охотников к приобретению навыков определения видов в природе и изучению их биологии, отсутствие системы контроля этих знаний при получении охотничьего билета.

Одним из вариантов решения обозначенной проблемы может стать введение обязательного экзамена по определению охотничьих животных, животных из списков Красных книг и не подлежащих добыче. Сознательность охотников, сдавших экзамен, должна увеличиться. Вместе с тем сформированная компетенция поможет повысить достоверность данных об охотничьем изъятии птиц, получаемых при ведении системы отчетности охотхозяйствами и охотобществами или посредством анкетирования охотников, для дальнейшей статистической обработки. Следует учесть возможность выбора охотниками способа подготовки к экзамену - самостоятельно, по специально созданным учебным по- 
собиям или пройдя обучение на соответствующих курсах со специалистом. Организационные расходы частично или полностью покроет новая государственная пошлина.

2. Сознательное нарушение правил охоты конкретными гражданами. Такие нарушения, помимо всего прочего, происходят вследствие формирующегося чувства безнаказанности, обусловленного невозможностью немногочисленным штатом сотрудников контролирующих органов осуществлять проверку охотников на большей части огромной малонаселенной территории, многие участки которой труднодоступны.

Исправить ситуацию можно, ужесточив штрафные санкции за нарушения правил охоты, в особенности за добычу животных, внесенных в Красные книги, искоренив коррупционную составляющую, изменив ментальность жадного или вороватого человека, что само по себе довольно сложно, привив населению охотничью культуру. Последнее возможно только при правильном воспитании, планомерном обучении и активной пропаганде охраны природы со стороны различных учреждений и средств массовой информации. Не самую последнюю роль в этом процессе будет играть и увеличение уровня благосостояния граждан.

3. Недостаток финансирования научных и охранных мероприятий в регионе. В ХМАО - Югре отсутствует специальная долговременная программа по мониторингу редких и уязвимых видов животных, понимание путей решения проблем, с ними связанных. Изучение охраняемых представителей проводится лишь в рамках обеспечения мероприятий по ведению Красной книги Ханты-Мансийского автономного округа - Югры и на некоторых особо охраняемых природных территориях (ООПТ). При проведении полевых работ по Красной книге часто не берутся в расчет оптимальные сроки орнитологических исследований, специфика учетов отдельных систематических групп, наиболее перспективные территории, где могут быть встречены конкретные виды птиц. А сами работы часто привязаны к ООПТ. Отчасти это происходит в силу ограниченного бюджета, когда комплексное исследование, направленное на изучение животных, растений и грибов, в силу экономии средств на транспорт проводится в одно время одной экспедиционной группой. Неизвестно, что происходит на огромных территориях, куда экспедиции не организуются. Также не следует забывать и о бюрократических издержках.

Согласно Докладу «Об экологической ситуации...» [4] в 2017 г. в ХМАО - Югре под эгидой Года экологии в России проведен ряд эколого-просветительских мероприятий, посвященных сохранению пискульки. Среди них природоохранный проект «Путешествие малого белолобого гуся (пискульки)», эколого-просветительские уроки на тему «Малый белолобый гусь (пискулька)» в школах округа, цикл программ и статей о причинах исчезновения пискульки на муниципальных телеканалах и в печатных изданиях, издание иллюстрированного методического буклета «Отличительные черты малого белолобого гуся (пискульки) (Anser erythropus)» для охотников. Тем не менее, остается открытым вопрос об эффективности и масштабности этих разовых мероприятий. Соответствующий анализ никем не производился. Так, например, в Сургутском управлении Службы по контролю и надзору в сфере охраны окружающей среды, объектов животного мира и лесных отношений XМАО - Югры методических буклетов нет, ничего не слышали о пискульке опрошенные нами в 2019 г. сургутские школьники и студенты (71 человек). Не дошла информация и до охотников с. Сытомино, с которыми мы общались. Несомненно, следует уделять особое внимание экологическому просвещению и пропаганде в сети Интернет - многие сайты очень популярны среди молодежи и охотников.

Итак, только комплексное решение существующих проблем может способствовать сохранению пролетных пискулек на территории ХМАО - Югры. Хочется надеяться, что определенная часть перечисленных нами мер будет принята к рассмотрению в ближайшем будущем.

\section{ЛИТЕРАТУРА}

1. Водно-болотные угодья России. Т. 1. Водно-болотные угодья международного значения / под общ. ред. В. Г. Кривенко. М.: ИПО «Профиздат». 1998.

2. Гаврин В. Ф., Кривенко В. Г., Иванов Г. К., Азаров В. И., Молочаев А. В., Линьков А. Б., Антипов А. М., Дебело П. В., Стопалов В. С. Особенности весеннего пролета водоплавающих птиц в Срединном регионе СССР // отв. ред. В. А. Забродин. Экология и охрана охотничьих птиц: сб. научных трудов. М. 1980. С. 5-45.

3. Головатин М. Г. Двуобье // Ключевые орнитологические территории России. Т. 2. Ключевые орнитологические территории международного значения в Западной Сибири. М. 2006. С. 65-67.

4. Доклад «Об экологической ситуации в Ханты-Мансийском автономном округе - Югре в 2017 году» // Служба по контролю и надзору в сфере охраны окружающей среды, объектов животного мира и лесных отношений ХантыМансийского автономного округа - Югры (Природнадзор Югры). Режим доступа: https:/prirodnadzor.admhmao.ru/ upload/iblock/e80/maket-doklada-2017.doc (дата обращения: 06.05.2019).

5. Ильяшенко В. Ю., Шаталкин А. И., Куваев А. В., и др. Редкие и находящиеся под угрозой исчезновения животные России: материалы к Красной книге Российской Федерации. М. 2018.

6. Красная книга Российской Федерации: (животные). М. 2001. 
7. Красная книга Ханты-Мансийского автономного округа - Югры: животные, растения, грибы / отв. ред. А. М. Васин, А. Л. Васина. Екатеринбург. 2013.

8. Литвин К. Е. Новые данные о миграциях гусей, гнездящихся в России. Обзор результатов дистанционного прослеживания // отв. ред. А. Б. Поповкина. Казарка: бюл. рабочей группы по гусеобразным Сев. Евразии. Т. 17. М. 2014. C. $13-45$.

9. Морозов В. В., Аарвак Т. Зимовка пискулек, гнездящихся на Полярном Урале // отв. ред. Е. Е. Сыроечковский (мл.). Казарка: бюл. рабочей группы по гусеобразным Сев. Евразии. №10. М. 2004. С. 156-162.

10. Морозов В. В., Сыроечковский Е. Е. Пискулька на рубеже тысячелетий // отв. ред. Е. Е. Сыроечковский (мл.). Казарка: бюл. рабочей группы по гусеобразным Сев. Евразии. №8. М. 2002. С. 233-276.

11. Розенфельд С. Как вернуть мониторинг водоплавающей дичи? Инновационные методы регулирования весенней охоты по данным многолетнего мониторинга на примере ЯмалоНенецкого автономного округа // Охота. 2015. № 5(201). C. $76-84$.

12. Розенфельд С. Б., Стрельников Е. Г. Инвентаризация и оценка состояния мест миграционных остановок пискульки на Нижней Оби. М. 2012. С. 182-185.

13. Розенфельд С. Б., Соловьев М. Ю., Киртаев Г. В., Рогова Н. В., Иванов М. Н. Оценка пространственнобиотопического распределения гусеобразных птиц в Ямало-Ненецком и Ханты-Мансийском округе (опыт использования сверхлегкой авиации) // Зоологический журнал. 2017. Т. 96. № 2. С. 201-221.

14. Романов А. А., Поспелов И. Н. Внутриконтинентальные пространственные связи пискулек (Anser erythropus) горно-субарктических регионов Центральной Палеарктики // Экология. 2010. № 1. С. 66-69.

15. Рябицев В. К. Птицы Сибири. Т. 2. М. 2010.

16. Anser erythropus // The IUCN Red List of Threatened Species. 2018. http://dx.doi.org/10.2305/IUCN.UK.20182.RLTS.T22679886A132300164.en

17. Lorentsen S. H., Øien I. J., Aarvak T. Migration of Fennoscandian lesser white-fronted geese Anser erythropus mapped by satellite telemetry // Biological Conservation. 1998. Vol. 84. № 1. P. 47-52. https://doi.org/10.1016/ S0006-3207(97)00088-8

18. Morozov V. V., Øien I. J., Aarvak T. Satellite tracking of Lesser White-fronted Goose from the East-European tundra in Russia // Norsk Ornitologisk Forening-Report. 2014. Vol. 5. P. 1.

19. Morozov V. V., Aarvak T., Øien I. J. Satellite tracking of Lesser White-fronted Geese from the East-European tundra in Russia in 2014 // Norsk Ornitologisk Forening-Report. 2015.

20. Morozov V. V., Øien I. J., Aarvak T. 2016. Monitoring and satellite tracking of Lesser White-fronted Geese from the Russian European tundra in 2015 // Norsk Ornitologisk Forening, BirdLife Norway. Report 2. 1-13.

21. Nankinov D. Lesser White-fronted Goose (Anser erythropus) migration routes, wintering sites and conservation in Western Eurasia // Gibier faune sauvage. 1992. Vol. 9. № SEP. P. 257-268.

22. Rozenfeld S., Strelnikov E. 2011. Survey of Lesser White-fronted Goose Anser erythropus in lower Ob River, Russia in autumn 2010 // ed. by I. J. Øien. Norwegian Ornithological Society, NOF-BirdLife Norway. Report 3. 1-25.

23. Rozenfeld S. et al. The results of autumn counts of Lesser White-fronted Goose and other geese species in the Ob valley and White-sea-Baltic flyway in September 2015 // Goose Bulletin. 2016. Vol. 21. P. 12-31.

24. Rozenfeld S. B., Kirtaev G. V., Rogova N. V., Soloviev M. Yu. Results of an aerial survey of the western population of Anser erythropus (Anserini) in autumn migration in Russia 2017 // Nature Conservation Research. 2019. Vol. 4. № 1. P. 1-8.

25. Markkola J. The Finnish Lesser White-fronted Goose EU Life/Nature project 1997œ2000. 1998.

26. Tolvanen P., Øien I. J., Ruokolainen K. Lesser White-fronted Goose conservation project Annual report 1999.

27. Øien I. J. et al. Mapping of migration routes of the Fennoscandian Lesser White-fronted Goose breeding population with profound implications for conservation priorities // Conservation of Lesser White-fronted Goose on the European migration route. Final report of the EU LIFE-Nature project. 2005. Vol. 2009. P. 12-18.

\section{REFERENCE}

1. Vodno-bolotnye ugod'ya Rossii (1998). Vodno-bolotnye ugod'ya mezhdunarodnogo znacheniya. pod obshch. red. V. G. Krivenko. Moscow. (In Russian).

2. Gavrin, V. F., Krivenko, V. G., Ivanov, G. K., .. \& Stopalov, V. S. (1980). Osobennosti vesennego proleta vodoplavayushchikh ptits v Sredinnom regione SSSR. In Ekologiya i okhrana okhotnich'ikh ptits: cb. nauchnykh trudov. Moscow. 5-45. (In Russian).

3. Golovatin, M. G. (2006). Dvuob'e. In Klyuchevye ornitologicheskie territorii Rossii. 2. In Klyuchevye ornitologicheskie territorii mezhdunarodnogo znacheniya v Zapadnoi Sibiri. Moscow. 65-67. (In Russian).

4. Doklad "Ob ekologicheskoi situatsii v Khanty-Mansiiskom avtonomnom okruge — Yugre v 2017 godu". Sluzhba po kontrolyu i nadzoru v sfere okhrany okruzhayushchei sredy, ob"ektov zhivotnogo mira i lesnykh otnoshenii Khanty-Mansiiskogo avtonomnogo okruga - Yugry (Prirodnadzor Yugry) (In Russian).

5. Il'yashenko, V. Yu., Shatalkin, A. I., \& Kuvaev, A. V. (2018). Redkie i nakhodyashchiesya pod ugrozoi ischeznoveniya zhivotnye Rossii: materialy k Krasnoi knige Rossiiskoi Federatsii. Moscow. (In Russian).

6. Krasnaya kniga Rossiiskoi Federatsii: (zhivotnye) (2001). Moscow. (In Russian).

7. Krasnaya kniga Khanty-Mansiiskogo avtonomnogo okruga - Yugry: zhivotnye, rasteniya, griby (2013). Ekaterinburg. (In Russian).

8. Litvin, K. E. (2014). Novye dannye o migratsiyakh gusei, gnezdyashchikhsya v Rossii. Obzor rezul'tatov distantsionnogo proslezhivaniya. Kazarka: byul. rabochei gruppy po guseobraznym Sev. Evrazii, 17. Moscow. 13-45. (In Russian).

9. Morozov, V. V., \& Aarvak, T. (2004). Zimovka piskulek, gnezdyashchikhsya na Polyarnom Urale // otv. red. E. E. Syroechkovskii (ml.). Kazarka: byul. rabochei gruppy po guseobraznym Sev. Evrazii, (10). Moscow. 156-162. (In Russian).

10. Morozov, V. V., \& Syroechkovskii, E. E. (2002). Piskul'ka na rubezhe tysyacheletii. Kazarka: byul. rabochei gruppy po guseobraznym Sev. Evrazii, (8). Moscow. 233-276. (In Russian). 
11. Rozenfel'd, S. (2015). Kak vernut' monitoring vodoplavayushchei dichi? Innovatsionnye metody regulirovaniya vesennei okhoty po dannym mnogoletnego monitoringa na primere Yamalo $\neg$ Nenetskogo avtonomnogo okruga. Okhota, 5(201). 76-84. (In Russian).

12. Rozenfel'd, S. B., \& Strel'nikov, E. G. (2012). Inventarizatsiya i otsenka sostoyaniya mest migratsionnykh ostanovok piskul'ki na Nizhnei Obi. Moscow. 182-185. (In Russian).

13. Rozenfel'd, S. B., Solov'ev, M. Yu., Kirtaev, G. V., Rogova, N. V., \& Ivanov, M. N. (2017). Otsenka prostranstvennobiotopicheskogo raspredeleniya guseobraznykh ptits v Yamalo-Nenetskom i Khanty-Mansiiskom okruge (opyt ispol'zovaniya sverkhlegkoi aviatsii). Zoologicheskii zhurnal, 96(2). 201-221. (In Russian).

14. Romanov, A. A., \& Pospelov, I. N. Vnutrikontinental'nye prostranstvennye svyazi piskulek (Anser erythropus) gornosubarkticheskikh regionov Tsentral'noi Palearktiki. Ekologiya, (1), 66-69.

15. Ryabitsev, V. K. (2014). Ptitsy Sibiri. Moscow. (In Russian).

16. Anser erythropus. (2018). In: The IUCN Red List of Threatened Species. http://dx.doi.org/10.2305/IUCN.UK.20182.RLTS.T22679886A132300164.en

17. Lorentsen, S. H., Øien, I. J., \& Aarvak, T. (1998). Migration of Fennoscandian lesser white-fronted geese Anser erythropus mapped by satellite telemetry. Biological Conservation, 84(1), 47-52. https://doi.org/10.1016/S0006-3207(97)00088-8

18. Morozov, V. V., Øien, I. J., \& Aarvak, T. (2014). Satellite tracking of Lesser White-fronted Goose from the EastEuropean tundra in Russia. Norsk Ornitologisk Forening-Report, 5, 1.

19. Morozov, V. V., Aarvak, T., \& Øien, I. J. (2015). Satellite tracking of Lesser White-fronted Geese from the EastEuropean tundra in Russia in 2014. Norsk Ornitologisk Forening-Report.

20. Morozov, V. V., Øien, I. J., \& Aarvak, T. (2016). In: Norsk Ornitologisk Forening, BirdLife Norway. Report 2. 1-13.

21. Nankinov, D. (1992). Lesser White-fronted Goose (Anser erythropus) migration routes, wintering sites and conservation in Western Eurasia. Gibier faune sauvage, 9(SEP), 257-268.

22. Rozenfeld, S., \& Strelnikov, E. (2011). In: Norwegian Ornithological Society, NOF-BirdLife Norway. ed. by I. J. Øien. Report 3. 1-25.

23. Rozenfeld, S., Kirtaev, G., Soloviev, M., Rogova, N., \& Ivanov, M. (2016). The results of autumn counts of Lesser Whitefronted Goose and other geese species in the Ob valley and White-sea-Baltic flyway in September 2015. Goose Bulletin, 21 , 12-32.

24. Rozenfeld,S. B., Kirtaev, G. V., Rogova, N. V., \& Soloviev,M. Yu. (2019): In: Nature Conservation Research, 4(1). 1-8.

25. Markkola, J. (1998). The Finnish Lesser White-fronted Goose EU Life/Nature project $1997 œ 2000$.

26. Tolvanen, P., Øien, I. J., \& Ruokolainen, K. (1999). Lesser White-fronted Goose conservation project Annual report.

27. Øien, I. J., Aarvak, T., Ekker, M., \& Tolvanen, P. (2005). Mapping of migration routes of the Fennoscandian Lesser White-fronted Goose breeding population with profound implications for conservation priorities. Conservation of Lesser Whitefronted Goose on the European migration route. Final report of the EU LIFE-Nature project, 2009, 12-18.

Емцев А. А., Поргунёв А. В. Дополнительные сведения о миграционных остановках пискульки в Сургутском районе Ханты-Мансийского автономного округа - Югры и проблема охраны вида // Вестник Нижневартовского государственного университета. 2020. № 1. С. 98-103. https://doi.org/10.36906/2311-4444/20-1/15

Emtsev, A. A., \& Porgunyov, A. V. (2020). Additional information about the lesser white-fronted goose migration stops in the Surgut district of the Khanty-Mansiysk autonomous okrug - Ugra and the problem of species conservation. Bulletin of Nizhnevartovsk State University, (1). 98-103. https://doi.org/10.36906/2311-4444/20-1/15 